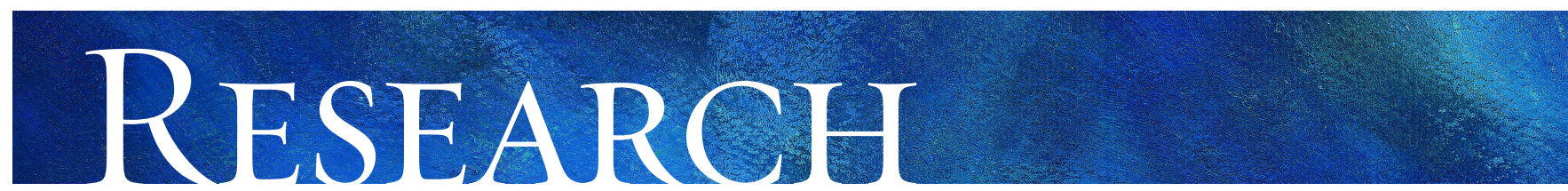

\title{
Systematic detection and multidisciplinary care of depression in older medical inpatients: a randomized trial
}

\author{
Martin G. Cole, Jane McCusker, Michel Elie, Nandini Dendukuri, Eric Latimer, Eric Belzile
}

Published at www.cmaj.ca on Dec. 5, 2005.

\section{ABSTRACT}

Background: Major depression is a frequent and serious disorder in older medical inpatients. Because the condition goes undetected and untreated in most of these patients, we conducted a randomized clinical trial to evaluate the effectiveness of a strategy of systematic detection and multidisciplinary treatment of depression in this population.

Methods: Consecutive patients aged $\sigma_{5}$ years or more admitted to general medical services in a primary care hospital between October 1999 and November 2002 were screened for depression with the Diagnostic Interview Schedule (DIS) within 48 hours after admission. Patients found to have major depression were randomly allocated to receive the intervention or usual care. The intervention involved consultation and treatment by a psychiatrist and follow-up by a research nurse and the patient's family physician. Research assistants, blind to group allocation, collected data from the patients at enrolment and at 3 and 6 months later using the Hamilton Depression Rating Scale (HAMD), the Medical Outcomes 36 -item Short Form (SF-36), the DIS, the Mini-Mental State Examination (MMSE), the Older Americans Resources and Services (OARS) questionnaire to assess basic and instrumental activities of daily living (OARS-ADL and OARS-IADL) and the Rating Scale for Side Effects. Data on the severity of illness, length of hospital stay, health services and medication use, mortality and process of care were also collected. The primary outcome measures were the HAMD and SF-36.

Results: Of 1500 eligible patients who were screened, 157 were found to have major depression and consented to participate ( 78 in the intervention group and 79 in the usual care group). At randomization, there were no clinically or statistically significant differences between the 2 groups. Sixty-four patients completed follow-up to 6 months, 57 withdrew, and 36 died. At 6 months, there were no clinically or statistically significant differences the 2 groups in HAMD or SF-36 scores or any of the secondary outcome measures.

Interpretation: We were unable to demonstrate that systematic detection and multidisciplinary care of depression was more beneficial than usual care for elderly medical inpatients.

CMAJ 2006;174(I):38-44
M ajor depression occurs in 10\%-30\% of older medical inpatients ${ }^{1-4}$ and appears to be associated with poor functional status, ${ }^{5}$ increased use of hospital services ${ }^{6,7}$ and reduced survival, ${ }^{6,8-10}$ independent of the severity of physical illness. Despite the apparent benefits of treatment, ${ }^{11}$ up to $90 \%$ of cases of depression are not detected by attending physicians during the course of usual hospital care, ${ }^{3,12}$ and few patients receive optimal treatment in hospital or after discharge. ${ }^{12,13}$ Because a strategy of systematic detection and treatment has been shown to benefit elderly people with depression living in the community, ${ }^{14-18}$ we conducted a randomized clinical trial to evaluate whether systematic detection and multidisciplinary treatment of depression could be effective in reducing symptoms of depression and improving mental and physical health status in elderly medical inpatients. Our secondary objective was to determine the effect of the intervention on basic and instrumental activities of daily living, cognitive status, side-effects profile, mortality and health services utilization (length of hospital stay, and number of readmissions and emergency department visits).

\section{Methods}

We conducted the study at St. Mary's Hospital Center, a university-affiliated, primary acute care hospital in Montréal. The trial was approved by the hospital's Research Ethics Committee.

All patients aged $6_{5}$ years and over admitted from the emergency department to medical services between Oct. I9, I999, and Nov. I, 2002, were screened for eligibility by the research nurse. We excluded patients who (a) were admitted to the intensive care unit or cardiac monitoring unit for more than 48 hours; (b) had an imminently terminal illness; (c) did not speak or understand English or French; and (4) did not live on the Island of Montreal. Eligible patients who scored 4 or less on the Short Portable Mental Status Questionnaire (indicating at most mild cognitive impairment) were assessed using the Diagnostic Interview Schedule. ${ }^{19}$ Patients who were found to have major depression (as defined by DSM-IV criteria $^{20}$ ) and who consented to participate were enrolled.

Enrolled patients were allocated to the intervention or usual-care groups with the use of block-size randomization and an allocation ratio of I:I. The block size was varied ran- 
domly to improve blinding. The study statistician prepared a series of sealed envelopes containing the treatment allocation. For each enrolled patient, the research nurse opened the next envelope on top of the pile to determine his or her group allocation.

The framework for the intervention was adapted from a methodology to assess geriatric services. ${ }^{21}$ The intervention group received systematic treatment for 24 weeks. The treatment was provided in 3 parts: (a) assessment and treatment by a psychiatrist in the hospital's geriatric service; (b) followup by the research nurse; and (c) follow-up by the patient's family physician. The psychiatrist assessed each patient and made management recommendations, all recorded on the regular hospital consultation form and signaled in the progress notes. Treatment involved supportive psychothera$\mathrm{py}^{22}$ and drug therapy with an antidepressant (e.g., a selective serotonin reuptake inhibitor [SSRI], a tricyclic antidepressant or methylphenidate), prescribed according to clinical practice guidelines. ${ }^{23}$ Patients were seen as often as necessary during their hospital stay and after discharge. When the patients were seen by their family physician for follow-up, the psychiatrist was informed of their progress by the research nurse. The research nurse visited the patients at least weekly in hospital and visited or telephoned them weekly after discharge for 24 weeks to monitor their condition, provide supportive psychotherapy, ensure maximum compliance with their treatment and liaise with the family, psychiatrist and family physician. The intervention team (comprising 2 psychiatrists from the geriatric service and the research nurse) met regularly to assure consistency in the diagnosis and management of depression.

Subjects assigned to the control group received usual care before and after discharge. There is no evidence that the proposed intervention improves outcomes of medical inpatients. This study proposed enhanced care for depressed patients and involved only the risks associated with accepted treatments of depression. Subjects in the usual-care group were informed that they had major depression and advised to discuss treatment with their physician, but they received no systematic intervention or follow-up. Hospital staff were not informed when usual-care subjects were enrolled in the study, in order to minimize contamination. Referrals for psythe intervention. chiatric consultation were honoured, consistent with usual practice.

Data were collected at baseline and at 3 and 6 months later by research assistants blind to group allocation. Measures at baseline included 3 measures of physical illness (Clinical Severity of Illness, ${ }^{24}$ the Charlson Comorbidity Index, ${ }^{25}$ and an acute physiology score, derived from 12 physiologic variables of APACHE II. ${ }^{26}$ Alcohol abuse was determined with the use of the CAGE questionnaire. ${ }^{27}$ Measures at baseline and follow-up included the Diagnostic Interview Schedule ${ }^{25}$ (symptoms were counted toward the diagnosis of depression regardless of their origin [physical illness or depression]); the 2I-item Hamilton Depression Rating Scale (HAMD); ${ }^{28}$ the

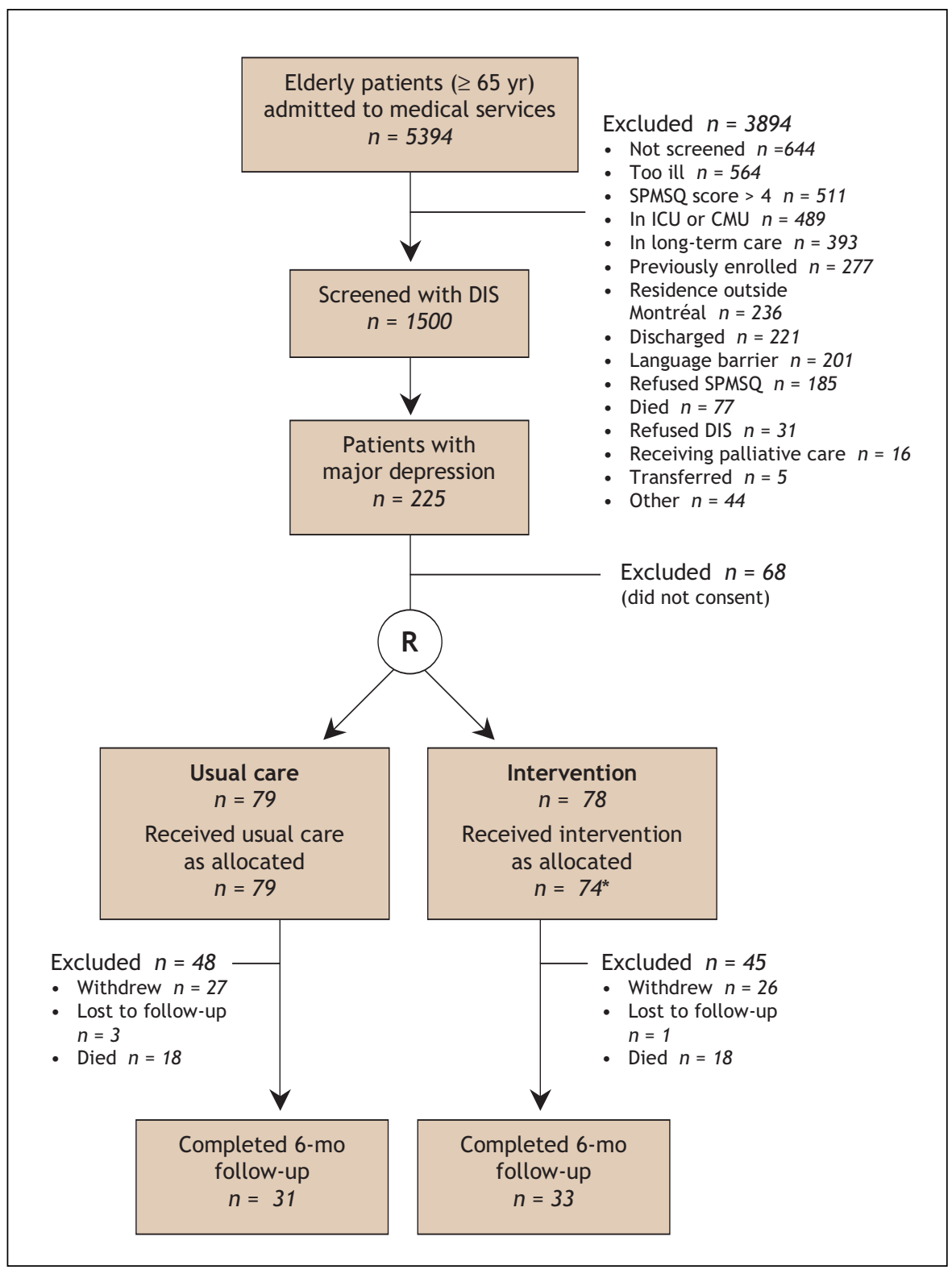

Fig. 1: Flow of patients through the trial. SPMSQ = Short Portable Mental State Questionnaire, ICU = intensive care unit, CMU = cardiac monitoring unit, DIS = Diagnostic Interview Schedule, $\mathrm{R}=$ randomization. ${ }^{\star}$ Three patients withdrew and 1 patient died before 
Medical Outcomes Study 36-item Short Form (SF-36); ${ }^{29}$ the Mini-Mental State Examination (MMSE); $;^{30}$ the Older Americans Resources and Services (OARS) questionnaire to assess basic and instrumental activities of daily living (OARS-ADL and OARS-IADL); ${ }^{31}$ and the Rating Scale for Side Effects (RSSE) $^{32}$ (modified to include the side effects of SSRIs and methylphenidate). Measures at follow-up included mortality, suicide and suicide attempts, and health services utilization (length of hospital stay, and number of readmissions and emergency department visits). Information about antidepressant use was collected from 3 sources: the hospital chart (drug use at admission and discharge), the research assistant's notes (drug use at the 6-month follow-up) and the provincial drug database (prescriptions filled I month before

Table 1: Baseline characteristics of elderly medical inpatients with major depression in the intervention and usual-care groups

\begin{tabular}{|c|c|c|}
\hline Characteristic & $\begin{array}{l}\text { Intervention } \\
\text { group } \\
n=78\end{array}$ & $\begin{array}{l}\text { Usual-care } \\
\text { group } \\
n=79\end{array}$ \\
\hline Age, mean (SD), yr & $77.5(6.7)$ & $78.5(6.6)$ \\
\hline Female sex, \% & 69.2 & 69.6 \\
\hline \multicolumn{3}{|l|}{ Living arrangement, \% } \\
\hline Home alone & 48.7 & 51.3 \\
\hline Home with spouse & 18.0 & 20.5 \\
\hline Home with family & 16.7 & 12.8 \\
\hline Other* & 16.7 & 15.4 \\
\hline Past history of depression, $\%$ & 14.5 & 15.4 \\
\hline $\begin{array}{l}\text { Duration of current depression } \\
\geq 2 \mathrm{yr}, \%\end{array}$ & 24.4 & 30.4 \\
\hline Alcohol use (CAGE score > 0), \% & 12.5 & 10.2 \\
\hline Has a confidant, \% & 74.6 & 84.2 \\
\hline $\begin{array}{l}\text { Death of someone close in past } \\
\text { year, \% }\end{array}$ & 46.8 & 42.9 \\
\hline \multicolumn{3}{|l|}{ Drug use, $\%$} \\
\hline Psychotropic & 46.2 & 53.2 \\
\hline Antidepressant & 25.6 & 27.9 \\
\hline Severity-of-illness score, mean (SD) & $4.3 \quad(0.9)$ & $4.2 \quad(1.1)$ \\
\hline HAMD score, mean (SD) & $21.3 \quad(5.5)$ & $20.1 \quad(5.9)$ \\
\hline \multicolumn{3}{|l|}{ SF-36 score, mean (SD) } \\
\hline Mental component & $37.4(10.9)$ & $34.3(13.2)$ \\
\hline Physical component & $32.8 \quad(7.2)$ & $33.9(11.7)$ \\
\hline MMSE score, mean (SD) & $24.9 \quad(3.5)$ & $23.8 \quad(4.9)$ \\
\hline OARS-ADL score, mean (SD) & $11.5 \quad(2.4)$ & $11.2 \quad(2.5)$ \\
\hline OARS-IADL score, mean (SD) & $9.6 \quad(2.9)$ & $9.6 \quad(2.5)$ \\
\hline RSSE score, mean (SD) & $18.3 \quad(6.5)$ & $18.2(6.7)$ \\
\hline Acute physiology score, mean (SD) & $2.5 \quad(2.3)$ & $2.2(2.0)$ \\
\hline $\begin{array}{l}\text { Charlson Comorbidity Index, } \\
\text { mean (SD) }\end{array}$ & $2.1 \quad(1.9)$ & $1.7 \quad(1.7)$ \\
\hline
\end{tabular}

Note: SD = standard deviation, HAMD = Hamilton Depression Rating Scale, SF-36 = Medical Outcomes Study 36-item Short Form, MMSE = Mini-Mental State Examination, OARS-ADL and OARS-IADL= Older Americans Resources and Services questionnaire assessing basic and instrumental activities of daily living, RSSE = Rating Scale for Side Effects.

*Includes foster home, senior residence and nursing home. admission, 2 months after discharge and 5-7 months after enrolment). The psychiatrists and the research nurse recorded their contacts with the patients, families, family physicians and each other.

The interrater agreement (kappa value) between the psychiatrist and research nurse and between the 2 research assistants for major versus no major depression was I.o $(n=9)$ and $0.78(n=28)$ respectively. The research assistants' intraclass correlation coefficient (ICC) was $0.99(n=28)$ for the HAMD and I.o $(n=18)$ for the SF- 36 . For the other measures, the ICC ranged from 0.99 to $\mathrm{I} .0(n=\mathrm{I} 4-28)$.

Intervention and control groups were compared at baseline. Patients who completed both baseline and follow-up interviews were compared with patients who withdrew from the study or died.

To evaluate the effect of the intervention, we estimated the difference between the intervention and control groups in the change in each primary outcome variable (i.e., HAMD, and SF-36 summary scores for the physical and mental health components) between baseline and the 6-month follow-up. An intention-to-treat approach was used. This analysis was based on all observed data with the assumption that data were missing at random.

Using the HAMD, we defined improvement in major depression as a decrease in the HAMD score of $50 \%$ or greater at 6 months compared with baseline; we defined remission of major depression as a HAMD score of less than 7 points at 6 months. We estimated the difference between the intervention and usual-care groups in the proportion of patients who showed improvement, remission or major depression (according to DSM IV criteria) at 6 months. We also estimated the difference between the 2 groups in the following outcomes: change from baseline to 6 months in the OARS-ADL, OARS-IADL, MMSE and RSSE scores, length of hospital stay, and incidence during the 6 months after baseline of admission to hospital, suicide or suicide attempts, visits to the emergency department and death.

For both primary and secondary outcomes, we compared continuous variables using the $t$ test and discrete variables using the Fisher's exact test. To compare length of stay during the index admission between the 2 groups, we used Wilcoxon's rank sum test because of the non-normal distribution of this variable. We report $95 \%$ confidence intervals for the differences in all outcomes. For differences in proportions, we calculated bootstrap confidence intervals because of the small samples. We repeated the analysis of both primary and secondary outcomes while adjusting for baseline characteristics of patients and process-of-care variables.

Although not planned in the protocol, we carried out additional analyses by including the 3-month data for the primary outcomes. A mixed-effects regression model was fit that adjusted for the dependence between multiple observations for each patient.

The dropout rate was high, and the resulting sample of patients with complete data had an underrepresentation of severely ill subjects. Therefore, we repeated our analysis of both primary and secondary outcomes by imputing missing data, with the last measure carried forward. This allowed us 
Table 2: Baseline characteristics of subjects who completed the study, withdrew or died

\begin{tabular}{|c|c|c|c|c|c|}
\hline Characteristic & $\begin{array}{c}\text { Completed study } \\
n=64\end{array}$ & $\begin{array}{l}\text { Withdrew } \\
n=57\end{array}$ & $p$ value $^{*}$ & $\begin{array}{c}\text { Died } \\
n=36\end{array}$ & $p$ value $\dagger$ \\
\hline Age, mean (SD), yr & $77.9(7.3)$ & $77.8(6.2)$ & 0.96 & $78.7(6.2)$ & 0.56 \\
\hline Female sex, \% & 75.0 & 79.0 & 0.61 & 44.4 & 0.002 \\
\hline Living arrangement, \% & & & 0.08 & & 0.58 \\
\hline Home alone & 44.4 & 52.6 & & 55.6 & \\
\hline Home with spouse & 23.8 & 10.5 & & 25.0 & \\
\hline Home with family & 11.1 & 22.8 & & 8.3 & \\
\hline Other $\neq$ & 20.6 & 14.0 & & 11.1 & \\
\hline Past history of depression, $\%$ & 16.1 & 17.9 & 0.81 & 8.3 & 0.14 \\
\hline Duration of current depression $\geq 2 \mathrm{yr}, \%$ & 29.7 & 29.8 & 0.99 & 19.4 & 0.26 \\
\hline Alcohol use (CAGE score > 0), \% & 16.1 & 6.3 & 0.44 & 3.7 & 0.16 \\
\hline Has a confidant, \% & 76.6 & 70.8 & 0.58 & 90.6 & 0.10 \\
\hline Death of someone close in past year, $\%$ & 49.2 & 36.0 & 0.26 & 43.8 & 0.62 \\
\hline \multicolumn{6}{|l|}{ Drug use, $\%$} \\
\hline Psychotropic & 56.3 & 40.4 & 0.08 & 52.8 & 0.74 \\
\hline Antidepressant & 31.3 & 21.1 & 0.20 & 27.8 & 0.72 \\
\hline Severity-of-illness score, mean (SD) & $3.9(0.8)$ & $4.3 \quad(1.0)$ & 0.016 & $4.7 \quad(1.2)$ & 0.001 \\
\hline HAMD score, mean (SD) & $20.7 \quad(5.5)$ & $21.0 \quad(6.8)$ & 0.84 & $20.8 \quad(5.3)$ & 0.93 \\
\hline \multicolumn{6}{|l|}{ SF-36 score, mean (SD) } \\
\hline Mental component & $36.3(12.1)$ & $35.9(14.4)$ & 0.90 & $35.5(10.4)$ & 0.77 \\
\hline Physical component & $33.8(10.2)$ & $31.5 \quad(9.2)$ & 0.42 & $33.0 \quad(7.2)$ & 0.74 \\
\hline MMSE score, mean (SD) & $24.6 \quad(3.7)$ & $24.9 \quad(3.4)$ & 0.73 & $23.7 \quad(5.5)$ & 0.39 \\
\hline OARS-ADL score, mean (SD) & $11.1(2.6)$ & $11.8 \quad(2.0)$ & 0.24 & $11.4 \quad(2.4)$ & 0.58 \\
\hline OARS-IADL score, mean (SD) & $9.6 \quad(2.9)$ & $9.9 \quad(2.4)$ & 0.67 & $9.4 \quad(2.7)$ & 0.82 \\
\hline RSSE score, mean (SD) & $18.0 \quad(6.0)$ & $18.9(7.9)$ & 0.62 & $18.3 \quad(6.9)$ & 0.86 \\
\hline Acute physiology score, mean (SD) & $2.3 \quad(2.3)$ & $2.1 \quad(1.8)$ & 0.62 & $2.9 \quad(2.4)$ & 0.27 \\
\hline Charlson Comorbidity Index, mean (SD) & $1.5 \quad(1.4)$ & 1.9 (1.9) & 0.21 & $2.6(1.8)$ & 0.001 \\
\hline
\end{tabular}

Note: SD $=$ standard deviation, HAMD $=$ Hamilton Depression Rating Scale, SF-36 = Medical Outcomes Study 36-item Short Form, MMSE $=$ Mini-Mental State Examination, OARS-ADL and OARS-IADL= Older Americans Resources and Services questionnaire assessing basic and instrumental activities of daily living, RSSE = Rating Scale for Side Effects.

* $p$ value comparing subjects who completed the study and those who withdrew from the study.

tp value comparing subjects who completed the study and those who died.

†Includes foster home, senior residence and nursing home.

to include data for all patients who had completed the baseline interview, which reduced the proportion of missing data from $50 \%$ to about $29 \%$. We also examined the sensitivity of the results by repeating the analyses after excluding (a) patients in the intervention group who did not receive a consultation and those in the control group who did receive a consultation, and (b) patients taking antidepressants at baseline.

The sample-size calculations were based on the formula for comparison of 2 means for one principal outcome, the HAMD. In a study involving elderly ambulatory patients, we had found a mean difference in HAMD scores between the intervention and usual-care groups of 5-7 points. ${ }^{33}$ Among physically ill and disabled elderly medical inpatients, we anticipated that the difference would be less (i.e., 4 points). On the basis of an estimated standard deviation of change in the HAMD score of $8.0,{ }^{34}$ we determined that 85 subjects would be required in each group to detect a change of at least 4 points in the HAMD score. However, because the attrition rate was higher than expected (6o\%), the sample-size calculation was repeated midway through the study. On the basis of a standard deviation of change in the HAMD score of 5.6 (derived from the data collected), we determined that 3I subjects in each group would be required to detect a change of at least 4 points in the HAMD score with $80 \%$ power and a 2 -sided significance level of 0.05 . Allowing for an attrition rate of $60 \%$, we needed to recruit 78 patients in each group.

\section{Results}

The flow of patients through the study is shown in Fig. I. Of the 1500 inpatients screened, 225 (15.0\%) were found to have major depression. There were no deviations from the study protocol. Of the 157 patients who consented to participate in the study, 78 were allocated to the intervention group and 79 to the usual-care group. At randomization, there were no clinically significant differences between the groups (Table I). 
Sixty-four subjects (40.8\%) completed the follow-up to 6 months; 57 (36.3\%) withdrew (almost all before 3 months), and $36(22.9 \%)$ died before the 6-month follow-up (Table 2). Those who withdrew had more severe physical illness than those who completed the 6-month follow-up. There were statistically significant differences in sex, severity of illness and Charlson Comorbidity Index scores between those who died and those who completed the 6-month follow-up.

Seventy-four patients $(94.9 \%)$ in the intervention group received a consultation, which occurred a mean I.2 days after enrolment; of the remaining 4 patients, 3 withdrew and I died. The mean number of follow-up contacts per patient by the psychiatrists and research nurse are presented in Table 3. Twenty-one patients $(26.6 \%)$ in the usual-care group received a consultation, which occurred a mean 2.4 days after enrolment.

The rates of antidepressant use in the intervention and usual-care groups are presented in Table 3 . There were differences in the rates by source of information (chart $\mathrm{v}$. provincial

Table 3: Process of care of subjects who completed the 6-month follow-up*

\begin{tabular}{|c|c|c|c|}
\hline Variable & $\begin{array}{l}\text { Intervention } \\
\text { group } \\
n=33\end{array}$ & $\begin{array}{l}\text { Usual-care } \\
\text { group } \\
n=31\end{array}$ & $p$ value \\
\hline \multicolumn{4}{|l|}{$\begin{array}{l}\text { Contacts by treating } \\
\text { psychiatrist, mean no. }\end{array}$} \\
\hline With the patient & 4.5 & 0.3 & \\
\hline $\begin{array}{l}\text { With the intervention } \\
\text { nurse }\end{array}$ & 9.4 & 0.0 & \\
\hline With the family & 0.3 & 0.0 & \\
\hline $\begin{array}{l}\text { With the family } \\
\text { physician }\end{array}$ & 0.1 & 0.0 & \\
\hline \multicolumn{4}{|l|}{$\begin{array}{l}\text { Contacts by research } \\
\text { nurse, mean no. }\end{array}$} \\
\hline With the patient & 16.7 & 0.0 & \\
\hline With the family & 2.9 & 0.0 & \\
\hline $\begin{array}{l}\text { With the family } \\
\text { physician }\end{array}$ & 0.8 & 0.0 & \\
\hline $\begin{array}{l}\text { Mean no. of psychiatry } \\
\text { outpatient visits }\end{array}$ & 2.5 & 0.3 & $<0.001$ \\
\hline \multicolumn{4}{|l|}{$\begin{array}{l}\text { Antidepressant use, } \\
\text { no. (\%) of patients }\end{array}$} \\
\hline \multicolumn{4}{|l|}{ At admission } \\
\hline Chart & $11(33.3)$ & $9(29.0)$ & 0.71 \\
\hline RAMQ & $9(27.3)$ & $11(35.5)$ & 0.48 \\
\hline \multicolumn{4}{|l|}{ At discharge } \\
\hline Chart & $19(57.6)$ & $11(35.5)$ & 0.08 \\
\hline RAMQ & $20(60.6)$ & $14(45.2)$ & 0.22 \\
\hline \multicolumn{4}{|l|}{ At 6-mo follow-up } \\
\hline Self-report & $19(57.6)$ & $11(35.5)$ & 0.08 \\
\hline RAMQ & $17(51.5)$ & $14(45.2)$ & 0.61 \\
\hline
\end{tabular}

Note: RAMQ = Régie de l'assurance maladie du Québec (provincial drug database). *Psychological treatment received by patients in the intervention and usual-care groups is not included here because we were unable to collect this information from the hospital chart or from the patients at follow-up. drug database v. self-report). Antidepressants were not recommended for $8(25 \%)$ of the intervention patients because their depressive symptoms were mild or because potential risks outweighed potential benefits.

At 6 months, there were no statistically significant differences between the intervention and usual-care groups in the primary outcomes (Table 4). There were no differences in the rates of improvement $(\geq 50 \%$ decrease in HAMD score) or in the rates of remission (HAMD score $<7$ ) of depression. There was a potentially clinically important (but not statistically significant) difference in the rates of major depression (intervention $45.5 \% \mathrm{v}$. control $56.7 \%$ ). The results were similar when 3 -month data were included.

In the secondary analyses, we found no important relations between the baseline patient characteristics (age, sex, living arrangement, severity of illness, Charlson Comorbidity Index, OARS-ADL, OARS-IADL or HAMD scores, or duration of depression), process-of-care variables (number and type of contacts, use of antidepressant medication) and outcomes.

The results of the sensitivity analysis of primary and secondary outcomes were similar to those of the main analysis.

\section{Interpretation}

We proposed to determine the effectiveness of a strategy of systematic detection and multidisciplinary care of depression in elderly medical inpatients. We were unable to demonstrate that the intervention was beneficial, perhaps because of the high patient attrition rate, the low number of contacts between patients and psychiatrists (mean 4.5), the suboptimal compliance with antidepressant medication or possible contamination of the usual-care group (patients in both groups were managed on the same units by the same attending physicians).

Our results are similar to those of a recently published trial of care management of anxiety and depression among elderly veteran inpatients. ${ }^{35}$ That intervention involved assessment by a multidisciplinary team and assignment of a case coordinator who engaged patients in treatment and follow-up. The rate of attrition through withdrawal and death was as high as our rate $(60 \%)$. As in our study, there were no significant benefits of the intervention.

Our study has several potential limitations. It was difficult to maintain the participation of physically ill and depressed subjects ( 57 withdrew, and 36 died); even though there were no important differences between the groups in rates of withdrawal or death and no clinically important differences in baseline characteristics between those who completed the study and those who withdrew, this attrition rate may have affected the results. A quarter of enrolled patients had been depressed for 2 or more years; these patients may have been less likely to respond to the intervention; however, we found no relation between duration of depression and outcomes. A quarter of enrolled patients were taking antidepressant medication on admission, which may have reduced the effect of the intervention; however, there were no differences in outcomes when those taking antidepressants at baseline were excluded from the analysis. Arguably, the intervention group 
Table 4: Effect of intervention on outcome measures

\begin{tabular}{|c|c|c|c|}
\hline Outcome measure & $\begin{array}{l}\text { Intervention } \\
\text { group } \\
n=33\end{array}$ & $\begin{array}{l}\text { Usual-care } \\
\text { group } \\
n=31\end{array}$ & $\begin{array}{c}\text { Difference } \\
\text { between groups } \\
(95 \% \mathrm{Cl})\end{array}$ \\
\hline \multicolumn{4}{|l|}{ Primary } \\
\hline \multicolumn{4}{|l|}{$\begin{array}{l}\text { Difference in mean score from baseline } \\
\text { to 6-mo follow-up }\end{array}$} \\
\hline HAMD & -6.3 & -5.0 & $-1.3(-4.9$ to 2.2$)$ \\
\hline SF-36, mental component & 9.4 & 9.2 & $0.2(-8.7$ to 8.9$)$ \\
\hline SF-36, physical component & -2.9 & -2.7 & $-0.2(-5.4$ to 5.0$)$ \\
\hline \multicolumn{4}{|l|}{ Secondary } \\
\hline $\begin{array}{l}\text { Improvement ( } \geq 50 \% \text { decrease in HAMD score } \\
\text { at } 6 \mathrm{mo} \text { ) }\end{array}$ & 28.1 & 20.0 & $8.1(-13.3$ to 29.3$)$ \\
\hline Remission (HAMD score $<7$ at $6 \mathrm{mo}$ ) & 15.6 & 16.7 & $-1.1(-19.4$ to 17.3$)$ \\
\hline Major depression (DSM-IV criteria) at 6 mo & 45.5 & 56.7 & $-11.2(-35.8$ to 13.3$)$ \\
\hline \multicolumn{4}{|l|}{$\begin{array}{l}\text { Difference in mean score from baseline } \\
\text { to } 6 \text {-mo follow-up }\end{array}$} \\
\hline OARS-ADL & -1.0 & -0.8 & $-0.2(-1.6$ to 1.3$)$ \\
\hline OARS-IADL & -1.4 & -1.0 & $-0.4(-2.0$ to 1.3$)$ \\
\hline MMSE & 1.5 & 0.9 & $0.6(-1.1$ to 2.2$)$ \\
\hline RSSE & -3.3 & -4.0 & $0.7(-2.6$ to 4.0$)$ \\
\hline Length of hospital stay (index admission), median, $d$ & 12.0 & 10.0 & $2.0(-6.5$ to 6.5$)$ \\
\hline \multicolumn{4}{|l|}{ Event during 6-mo follow-up, \% } \\
\hline Readmission & 39.4 & 29.0 & $10.4(-21.3$ to 23.5$)$ \\
\hline Suicide or suicide attempt & 3.2 & 3.3 & $0.1(-9.8$ to 9.4$)$ \\
\hline Any visit to emergency department & 45.5 & 41.9 & $3.6(-24.5$ to 24.7$)$ \\
\hline Mortality at 6-mo follow-up, \% & $\begin{array}{c}n=78 \\
23.1\end{array}$ & $\begin{array}{c}n=79 \\
22.8\end{array}$ & $0.3(-12.5$ to 13.1$)$ \\
\hline
\end{tabular}

Note: $\mathrm{Cl}=$ confidence interval, $\mathrm{HAMD}=$ Hamilton Depression Rating Scale, SF-36 = Medical Outcomes Study 36-item Short Form, MMSE = Mini-Mental State Examination, OARS-ADL and OARS-IADL= Older Americans Resources and Services questionnaire assessing basic and instrumental activities of daily living, RSSE = Rating Scale for Side Effects.

could have received interpersonal or cognitive-behavioural therapy (in addition to the antidepressant medication), but these therapies were not feasible in our study. The low number of follow-up contacts between the treating psychiatrists and the patients (mean 4.5), ostensibly owing to difficulties in attending clinic after discharge, may also have reduced the effect of the intervention; however, the number of contacts between the research nurse, patients, psychiatrists, family members and family physicians facilitated implementation of the intervention. Patients in both groups were managed on the same units by the same attending physicians; consequently, there may have been contamination of usual care by the intervention program, or there may have been a Hawthorne effect, whereby implementation of the study resulted in improved detection and care of all patients with depression. In the usual-care group, the rates of request for psychiatric consultation and antidepressant therapy prescribed at discharge were $26.6 \%$ and $35.5 \%-45.2 \%$, respectively, much higher than reported in descriptive studies. ${ }^{3,12,13}$ Controvertibly, the rate of antidepressant use in the usual-care group was high $(29 \%-35.5 \%)$ on admission.

These results are disappointing, but they should not dis- courage future trials of innovative interventions for the detection and management of depression in elderly inpatients. Such interventions might include extensive patient and family education, more aggressive pharmacotherapy, physical rehabilitation to improve activities of daily living, enhanced social supports or modified cognitive-behavioural therapy for the helplessness and disempowerment often associated with declining physical health. Finally, it may be necessary to use cluster randomization or a nonrandomized study design instead of randomization, to avoid contamination of the usual care.

This article has been peer reviewed.

From the Departments of Psychiatry (Cole, Elie) and of Clinical Epidemiology and Community Studies (McCusker), St. Mary's Hospital and McGill University, Montréal, Que.; the Department of Epidemiology and Biostatistics, McGill University, and the Technology Assessment Unit, McGill University Health Centre (Dendukuri); Services, Policy and Population Health Research Theme, Douglas Hospital Research Centre (Latimer); and the Department of Clinical Epidemiology and Community Studies, St. Mary's Hospital (Belzile)

Competing interests: None declared for Martin Cole, Jane McCusker, Nandini Dendukuri, Eric Latimer or Eric Belzile. Michel Elie has received speaker fees from Wyeth and Lundbeck. 
Contributors: Martin Cole, Jane McCusker and Nandini Dendukuri contributed to the conception and design of the study, the analysis and interpretation of the data, and the drafting and revision of the article. Michel Elie contributed to the acquisition, analysis and interpretation of the data and the revision of the article. Eric Latimer and Eric Belzile contributed to the analysis and interpretation of the data, and the revision of the article. All of the authors approved the final version for publication.

Acknowledgement: This study was funded by the Canadian Institutes of Health Research (grant no. MCT-I5476).

\section{REFERENCES}

I. Koenig HG, George LK, Petersen BL, et al. Depression in medically ill hospitalized older adults: prevalence, characteristics, and course of symptoms according to six diagnostic schemes. Am J Psychiatry 1997;154:1376-83.

2. Cooper B. Psychiatric disorders among elderly patients admitted to hospital medical wards. JR Soc Med 1987;80:13-6.

3. Rapp SR, Parisi SA, Walsh DA. Psychological dysfunction and physical health among elderly medical inpatients. J Consult Clin Psychol I $988 ; 56: 85 \mathrm{I}-5$

4. Fenton FR, Cole MG, Engelsmann F, et al. Depression in older medical inpatients. Int J Geriatr Psychiatry I997;12:389-94.

5. Covinsky KE, Fortinsky RH, Palmer RM, et al. Relation between symptoms of depression and health status outcomes in acutely ill hospitalized older persons. Ann Intern Med 1997;126:417-25.

6. Koenig HG, Shelp F, Goli V, et al. Survival and health care utilization in elderly medical inpatients with major depression. J Am Geriatr Soc 1989;37:599-606.

7. Fulop G, Strain JJ, Stettin G. Congestive heart failure and depression in older adults: clinical course and health services use 6 months after hospitalization. Psychosomatics 2003;44:367-73

8. Covinsky KE, Kahana E, Chin MH, et al. Depressive symptoms and 3-year mortality in older hospitalized medical patients. Ann Intern Med I999;I 30:563-9.

9. Von Ammon Cavanaugh SA, Furlanetto LM, Creech SD, et al. Medical illness, pas depression, and present depression: a descriptive triad for in-hospital mortality. Am J Psychiatry 2001;158:43-8

I0. Cole MG, Bellavance F. Depression in elderly medical inpatients: a meta-analysis of outcomes. CMAJ I997; $157(8): 1055-60$.

II. Cole MG, Elie LM, McCusker J, et al. Feasibility and effectiveness of treatments for depression in elderly medical inpatients: a systematic review. Int Psychogeriatr 2000;I2:453-6r

I2. Koenig HG, Goli V, Shelp F, et al. Major depression in hospitalized medically ill older men: documentation, management, and outcome. Int J Geriatr Psychiatry I992;7:25-34

I3. Koenig HG, George LK, Meador KG. Use of antidepressants by nonpsychiatrists in the treatment of medically ill hospitalized depressed elderly patients. Am J Psychiatry $1997 ; 154: 1369-75$.

I4. Banerjee S, Shamash K, Macdonald AJD, et al. Randomised controlled trial of effect of intervention by psychogeriatric team on depression in frail elderly people at home. BMJ I996;313:1058-61.

I5. Unutzer J, Katon W, Callahan CM, et al. Collaborative care management of late-life depression in the primary care setting. A randomized controlled trial. JAMA 2002; 288:2836-45.

I6. Blanchard MR, Waterreus A, Mann AH. The effect of primary care nurse intervention upon older people screened as depressed. Int J Geriatr Psychiatry I995;10:289-98.

I7. Flaherty JH, McBride M, Marzouk S, et al. Decreasing hospitalization rates for older home care patients with symptoms of depression. J Am Geriatr Soc I998;46:3I-8.

I8. Bruce ML, Ten Have TR, Reynolds CF III, et al. Reducing suicidal ideation and depressive symptoms in depressed older primary care patients. JAMA 2004;201:I08I-9I.

I9. Robins LN, Helzer JE, Croughan J, et al. National Institute of Mental Health Diag nostic Interview Schedule: its history, characteristics, and validity. Arch Gen Psychiatry $\mathrm{I} 98 \mathrm{I} ; 38: 38 \mathrm{I}-9$.

20. American Psychiatric Association. Diagnostic and statistical manual of mental dis orders. 4th ed. Washington: American Psychiatric Association; 1994

2I. Cole MG. Assessing the effectiveness of geriatric services: a proposed methodology. CMAJI993;I48(6):939-44.

22. Ursano RJ, Silberman EK. Psychoanalysis, psychoanalytic psychotherapy and supportive psychotherapy. In: Hales RE, editor. Textbook of psychiatry. 2nd ed. Washington: American Psychiatric Press; I994. p. 1035-6o.

23. Depression Guideline Panel. Depression in primary care. Vol 2: Treatment of major depression [Clinical Practice Guideline no 5]. Rockville (MD): US Departmen of Health and Human Services, Public Health Service, Agency for Health Care Policy and Research; I993. AHCPR Publ no 93-055I.
24. Charlson ME, Sax FL, MacKenzie R, et al. Assessing illness severity: Does clinical judgment work? JChronic Dis I986;39:439-52.

25. Charlson ME, Pompei P, Ales KL, et al. A new method of classifying prognostic comorbidity in longitudinal studies: development and validation. J Chronic Dis I987; 40:373-83.

26. Knaus W, Draper E, Wagner D, et al. APACHE II: a severity of disease classification system. Crit Care Med 1985;13:818-29.

27. Ewing JA. Detecting alcoholism: the CAGE questionnaire. JAMA I984;252:1905-7.

28. Hamilton M. Development of a rating scale for primary depressive illness. Br J SoC Clin Psychol r967;6:278-96.

29. Ware JE Jr, Sherbourne CD. The MOS 36 -item short-form health survey (SF-36). I. Conceptual framework and item selection. Med Care I992;30(6):473-83.

3o. Folstein MF, Folstein SE, McHugh PR. "Mini-mental State": a practical method for grading the cognitive state of patients for the clinician. J Psychiatr Res I975; I2: $189-98$

31. Fillenbaum GG. Multidimensional functional assessment of older adults: the Duke Older Americans Resources and Services procedures. Mahwah (NJ): Lawrence Erlbaum Associates Inc.; I988.

32. Asberg M, Cronholm B, Sjoqvist F, et al. Correlation of subjective side effects with plasma concentrations of nortriptyline. BMJ I970;4:I8-2I.

33. McCusker J, Cole M, Keller E, et al. Effectiveness of treatments of depression in older ambulatory patients. Arch Intern Med I998;158:705-I2

34. Tollefson GD, Holman SL. Analysis of the Hamilton Depression Rating Scale factors from a double-blind, placebo-controlled trial of fluoxetine in geriatric major depression. Int Clin Psychopharmacol I993;8:253-9.

35. Oslin DW, Thompson R, Kallan MJ, et al. Treatment effects from UPBEAT: a randomized trial of care management for behavioral health problems in hospitalized elderly patients. J Geriatr Psychiatry Neurol 2004;17:99-106.

Correspondence to: Dr. Martin G. Cole, Department of Psychiatry, St. Mary's Hospital Center, 3830 Lacombe Ave., Montréal QC $\mathrm{H}_{3} \mathrm{~T} \mathrm{IM}_{5}$; fax $5 \mathrm{I} 4$ 734-2652; martin.cole@ssss.gouv.qc.ca

\section{Editor's take}

- Most elderly medical inpatients have serious chronic diseases, and many have a limited life expectancy because of their disease burden. It is not surprising that major depression is prevalent among these patients; however, the condition goes undetected and untreated in most cases. Will a strategy of systematic detection and multidisciplinary management of depression help these patients?

- Consecutive elderly patients admitted to medical services in a primary care hospital who were found to have major depression were randomly assigned to receive the intervention or usual care. The intervention involved assessment and treatment by a psychiatrist and follow-up by a nurse and the patient's family physician.

- No benefit from the intervention could be shown. The finding is limited by the power of the study and the fact that some of the patients in the usual-care group received treatment for depression.

Clinical implications: No additional benefit was found for more intensive surveillance and treatment of major depression in medical inpatients. More study is needed, but any undetermined benefit is likely to be small. 